\title{
Subdural Hematoma and Postdural Puncture Headache from Intrathecal Pump Placement Resolved with Lumbar Epidural Blood Patch
}

\author{
Andrew Ng, Victor Romo, Dajie Wang \\ Department of Anesthesiology, Thomas Jefferson University Hospital, Philadelphia, PA, USA \\ Email: Andrew.Ng@jefferson.edu, Dajie.Wang@jefferson.edu
}

Received 24 July 2014; revised 25 August 2014; accepted 10 September 2014

Copyright (C) 2014 by authors and Scientific Research Publishing Inc.

This work is licensed under the Creative Commons Attribution International License (CC BY). http://creativecommons.org/licenses/by/4.0/

(c) (i) Open Access

\begin{abstract}
Intrathecal drug delivery systems are commonly used in the management of chronic pain, cancer pain and neuromuscular disorders with muscle spasticity. The complications associated with intrathecal pump placement include persistent cerebrospinal fluid (CSF) leak, hygroma, meningitis, and granuloma formation. A severe persistent CSF leak may cause postdural puncture headache along with acute intracranial subdural hematoma, which can be potentially life threatening. Surgical exploration with dural repair is required to treat this severe complication when conservative treatments fail. We present a case report of severe persistent CSF leak after intrathecal pump revision that resulted in a subdural hematoma and postdural puncture headache. In this case, an epidural blood patch was performed using epidural catheter under fluoroscopic guidance to target the site of CSF leak and to avoid damaging the intrathecal catheter. This patient's headache was resolved and intrathecal catheter remained intact after this blood patch.
\end{abstract}

\section{Keywords}

Postdural Puncture Headache, Subdural Hematoma, Intrathecal Pump, Epidural Blood Patch

\section{Introduction}

Intrathecal administration of medications has been a valuable treatment option for patients who suffer from chronic cancer pain. This is especially true for patients who were previously opioid responsive and developed opioid tolerance, or suffered intractable side effects, such as somnolence, pruritus, and nausea [1]. Continuous 
delivery of intrathecal baclofen may benefit patients with neuromuscular disorders that have progressive muscle spasticity and have failed oral muscle relaxant therapies [2]. With the increasing utilization of intrathecal drug delivery systems in clinical practice, it is important to be aware of the complications associated with this intervention and the appropriate management of these complications. The most common complications associated with intrathecal catheter placement include postdural puncture headache, persistent cerebrospinal fluid leak (CSF), hygroma, infection, meningitis, granuloma formation, neurological injury and medication errors [3]. Persistent CSF leak is a challenging complication that may require surgical exploration with dural repair. We are reporting a case of a patient who had undergone a revision of an intrathecal pump catheter and developed a postdural puncture headache, along with an acute intracranial subdural hematoma, believed to be secondary to a severe CSF leak. This patient was managed successfully with a targeted fluoroscopic guided epidural blood patch at the site of the CSF leak.

\section{Case Report}

This is a 48 year old male with a history of primary lateral sclerosis, who initially noticed weakness in the right upper extremity. This weakness gradually progressed to his bilateral lower extremities. He also developed severe extensor spasms in the bilateral lower extremities and right upper extremity. These spasms have limited his ability to ambulate, and have resulted in multiple falls that led to a distal femoral fracture, a metatarsal fracture and meniscal tears. He has tried numerous oral muscle relaxants including diazepam, cyclobenzaprine, and up to $80 \mathrm{mg}$ of baclofen daily, unfortunately, none of these medications provided him with adequate improvement of the spasticity. His past medical history included hypertension, obstructive sleep apnea, osteoporosis, and obesity.

Physical examination revealed significantly increased tone in the right upper extremity with Ashworth Scale of 3 at shoulder, elbow flexors and extensors, wrist flexors and extensors and finger flexors. The left upper extremity has Ashworth Scale of 1 . Upper extremities muscle strength test was 4/5. In the lower extremities, he had Ashworth Scale of 3 across most joints. Lower extremities muscle strength test was 4/5.

An intrathecal baclofen trial was subsequently performed due to his poor response to oral muscle relaxants. Since the patient had a successful trial of intrathecal baclofen, neurosurgery proceeded with the placement of an intrathecal pump. During placement, the intrathecal catheter was placed at the spinal canal at L2-L3 interlaminar space and the tip advanced to approximately T7 level. A Medtronic Synchromed ${ }^{\circledR}$ II programmable pump was implanted without any complications.

The patient did well until postoperative day six. On that day, he developed fever, tachycardia and worsening baseline spasticity. These symptoms were consistent with baclofen withdrawal. A nuclear medicine study was ordered to address the possibility of catheter breakdown. This study demonstrated no tracer activity in the intrathecal catheter or the thoracic cerebrospinal fluid. Both the pump and intrathecal catheter were immediately removed and replaced. For the intrathecal pump and catheter replacement, the catheter entered the spinal canal at L1-L2 interlaminar space and the tip of the catheter was advanced to approximately T9 level.

One day after the replacement of pump and catheter, this patient developed positional headaches in the frontal and occipital regions, along with nausea. A head CT obtained on postoperative day three was unremarkable. Despite IV hydration and caffeine treatment, this patient continued to have worsening headaches and nausea. A repeat head CT on postoperative day five revealed a new acute $4 \mathrm{~mm}$ subdural hematoma, along the left frontal convexity without midline shift. His neurological examination remained stable. His platelet count and coagulation profile was normal. The patient was not on any anticoagulation medications. Therefore, the subdural hematoma was concluded that it was due to severe CSF leak and associated intracranial hypotension.

Anesthesiology was consulted for an epidural blood patch. The decision was made to proceed with a fluoroscopic guided epidural blood patch to target L1-L2 region which is the needle entry site for intrathecal catheter placement. The procedure note is as follows: a $3 \frac{1}{2}$ inch 18 gauge Hustead needle was used to access the epidural space at L2-L3 interlaminar space under fluoroscopic guidance. After the Hustead needle was successful advanced into epidural space with loss of resistance at L2-L3 interlaminar space, a Braun Perifix ${ }^{\circledR} 20 \mathrm{G}$ epidural catheter was passed through the needle and advanced to the L1 level. This was confirmed with epidural contrast spread. A total of $18 \mathrm{ml}$ of venous blood was then injected through the epidural catheter. The patient reported that the intensity of the headaches improved from 7/10 to 3/10. 
On postoperative day one, the patient's headaches and nausea completely resolved. A repeat head CT demonstrated a stable subdural hematoma along the left frontal convexity. He was discharged to acute rehabilitation unit two days after the epidural blood patch. Over the next 3 month period, the patient remained headache free and his intrathecal baclofen pump dose was gradually titrated up to $267 \mathrm{mcg} /$ day. His mobility improved significantly from being wheelchair bound to walking with assistance on a walker. Moreover, he was able to increase the use of his dominant right hand.

\section{Discussion}

One of the known complications of intrathecal drug delivery system is cerebrospinal fluid (CSF) leak due to a dural puncture during placement of an intrathecal catheter [4]. The reduction of CSF volume and pressure may lead to intracranial hypotension, and manifest as positional headaches. These headaches are typically aggravated by standing and relieved in a supine position. Most headaches are typically benign and are self-limiting after 5 7 days [5].

Persistent CSF leakage may result in acute intracranial subdural hematoma [6]. Patients with prolonged headaches lasting more than 5 days and/or with focal neurological deficits should raise the suspicion of an intracranial subdural hematoma. The loss of CSF can lead to low intracranial pressure and possible enlargement of dural venous sinuses that increases the risk of a spontaneous subdural hematoma [6] [7]. The caudal displacement of the brain further increases the tension of dural venous sinuses, which may result in venous tears [5]. Intracranial hypotension can produce small subdural fluid collections that stretch and rupture large cortical veins, and lead to subdural hematomas.

The management of symptomatic persistent CSF leak can be divided into conservative and invasive treatments. In general, most patients will benefit from reassurance that postdural puncture headaches are usually selflimiting. A simple oral analgesic regimen such as non-steroidal anti-inflammatory drugs or opioids is usually effective in treating positional headaches. Although aggressive fluid hydration has not been shown to have any therapeutic benefit, patients with intracranial hypotension should be euvolemic [8]. Caffeine is a potent cerebral vasoconstrictor and it has been shown that patients had better headache relief compared to placebo [9] [10]. However, due to the stimulating effects of caffeine on the central nervous system, patients may experience insomnia that may attribute to a worsening of the headaches. There are several case reports that have documented seizures and decreased cerebral blood flow after administration of caffeine [11] [12]. In any cases of post-lumbar puncture headache that do not respond to conservative therapies, an epidural blood patch should be considered in a timely fashion for headache relief and to avoid life-threatening intracranial hypotension.

In this case, multiple attempts to place intrathecal catheter may have resulted in more severe CSF leak and intracranial hypotension. Persistent low pressure headache from intrathecal catheter placement may require surgical exploration and repair of the dural defect at the catheter site [13]. A less invasive approach would be a lumbar epidural blood patch [14]. Although the exact mechanisms of epidural blood patch are unknown, it has been hypothesized that the venous blood injected into the epidural space increases CSF pressure and forms a gelatinous plug over the dural defect, hence minimizing the CSF leak and allowing the dura to heal [8]. The potential complications related to lumbar epidural blood patch include back pain, paresthesia, CSF leaks and meningitis [8], and specifically in this case, the possibility of intrathecal catheter damage from the epidural blood patch needle. To avoid this problem and precisely target the site of CSF leak, the epidural space was entered at L2-L3 interlaminar space and a multiorifice epidural catheter was utilized to target the intrathecal catheter entry site, which is most likely the site of dural leak.

It is worth noting that the level of lumbar interlaminar space at which the intrathecal catheter is placed is crucial in order to avoid spinal cord injuries. Particular attention should be focused on the level of conus medullaris. The level of the consus medullaris is variable, ranging between middle third T12 to upper third L3 vertebrae. About 30\% of patient population has a mean conus position at the lower third L1 vertebrae [15]. The lumbar spine MRI was reviewed in this case, the conus medullaris ended at the superior end plate of L1 verterbra. Therefore neurological deficits was avoided with intrathecal catheter entered at L1-L2 interlaminar space.

\section{Conclusion}

In conclusion, most CSF leaks can be treated with conservative management and are usually self-limiting. An intracranial imaging study should be considered if the patient has neurological deficits. If the CSF leak 
progresses and an intracranial subdural hematoma develop, interventions should not be delayed in an attempt to avoid permanent neurological injuries. A less invasive approach with fluoroscopic guided epidural blood patch with an epidural catheter to target the site of the CSF leak can be effective treatment for patients with persistent CSF leak around the intrathecal catheter.

\section{References}

[1] Hassenbusch, S.J., Pillay, P.K., Magdinec, M., et al. (1990) Constant Infusion of Morphine for Intractable Cancer Pain Using an Implanted Pump. Journal of Neurosurgery, 73, 405-409. http://dx.doi.org/10.3171/jns.1990.73.3.0405

[2] Stempien, L. and Tsai, T. (2000) Intrathecal Baclofen Pump Use for Spasticity: A Clinical Survey. American Journal of Physical Medicine \& Rehabilitation, 79, 536-541. http://dx.doi.org/10.1097/00002060-200011000-00010

[3] Singh, P.K., Jain, R., et al. (2008) Management of Pericatheter Cerebrospinal Fluid Leak after Intrathecal Implantation of a Drug Delivery System. American Journal of Hospice and Palliative Care, 25, 237-239. http://dx.doi.org/10.1177/1049909108315520

[4] Sciubba, D.M., Kretzer, R.M. and Wang, P.P. (2005) Acute Intracranial Subdural Hematoma Following a Lumbar CSF Leak Caused by Spine Surgery. Spine, 30, E730-E732. http://dx.doi.org/10.1097/01.brs.0000192208.66360.29

[5] Gaucher Jr., D.J. and Perez Jr., J.A. (2002) Subdural Hematoma Following Lumbar Puncture. Archives of Internal Medicine, 162, 1904-1905. http://dx.doi.org/10.1001/archinte.162.16.1904

[6] Francia, A., Parisi, P., Vitale, A.M. and Esposito, V. (2001) Life-Threatening Intracranial Hypotension after Diagnostic Lumbar Puncture. Neurological Sciences, 22, 385-389. http://dx.doi.org/10.1007/s100720100069

[7] McHardy, F.E., Bayly, P.J. and Wyatt, M.G. (2001) Fatal Subdural Haemorrhage Following Lumbar Spinal Drainage during Repair of Thoraco-Abdominal Aneurysm. Anaesthesia, 56, 168-170. http://dx.doi.org/10.1046/j.1365-2044.2001.01786-2.x

[8] Chestnut, D.H. (2004) Obstetric Anesthesia Principles and Practice. Mosby-Yearbook, St. Louis.

[9] Sechzer, P.H. and Abel, L. (1978) Post Spinal Anesthesia Headache Treated with Caffeine. Current Therapeutic Research, 24, 307-331.

[10] Camann, W.R., Murray, R.S., Mushlin, P.S. and Lambert, D.H. (1990) Effects of Oral Caffeine on Post Dural Puncture Headaches: A Double-Blinded, Placebo-Controlled Trial. Anesthesia \& Analgesia, 70, 181-184. http://dx.doi.org/10.1213/00000539-199002000-00009

[11] Bolton, V.E., Leicht, C.H. and Scanlon, T.S. (1989) Postpartum Seizures after Epidural Blood Patch and Intravenous Caffeine. Anesthesiology, 70, 146-149. http://dx.doi.org/10.1097/00000542-198901000-00029

[12] Dodd, J.E., Efird, R.C. and Rauck, R.L. (1989) Cerebral Blood Flow Changes with Caffeine Therapy for Post Dural Headaches. Anesthesiology, 71, A679. http://dx.doi.org/10.1097/00000542-198909001-00679

[13] Friedberg, S.R. (2005) Surgical Management of Cerebrospinal Fluid Leakage after Spinal Surgery. In: Quinones-Hinojosa, A., Ed., Schmidek and Sweet's Operative Neurosurgical Techniques: Indications, Methods and Results. 5th Edition, WB Saunders, Philadelphia, 2147-2152.

[14] Oedit, R., van Kooten, F., Bakker, S.L.M. and Dippel, D.W.J. (2005) Efficacy of the Epidural Blood Patch for the Treatment of Post Lumbar Puncture Headache BLOPP: A Randomised, Observer-Blind, Controlled Clinical Trial. BMC Neurology, 5, 12. http://dx.doi.org/10.1186/1471-2377-5-12

[15] Lee, C.H., Seo, B.K., et al. (2004) Using MRI to Evaluate Anatomic Significance of Aortic Bifurcation, Right Renal Artery, and Conus Medullaris when Locating Lumbar Vertebral Segments. American Journal of Roentgenology, 182, 1295-1300. http://dx.doi.org/10.2214/ajr.182.5.1821295 
Scientific Research Publishing (SCIRP) is one of the largest Open Access journal publishers. It is currently publishing more than 200 open access, online, peer-reviewed journals covering a wide range of academic disciplines. SCIRP serves the worldwide academic communities and contributes to the progress and application of science with its publication.

Other selected journals from SCIRP are listed as below. Submit your manuscript to us via either submit@scirp.org or Online Submission Portal.
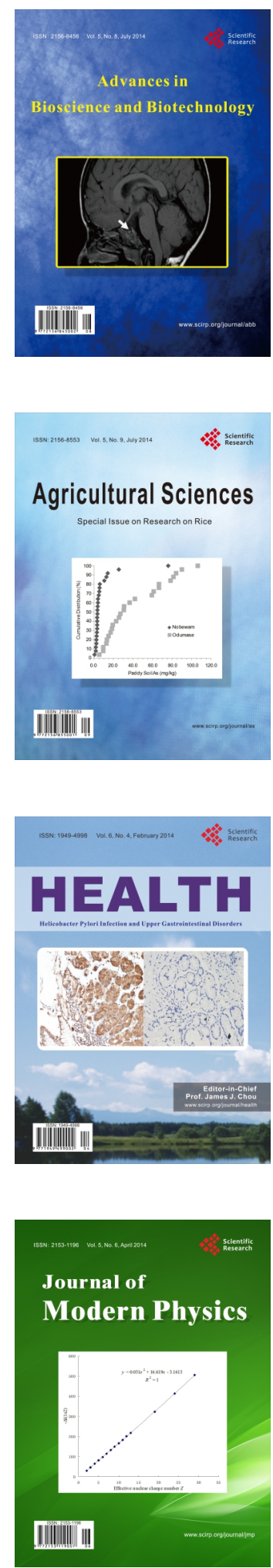
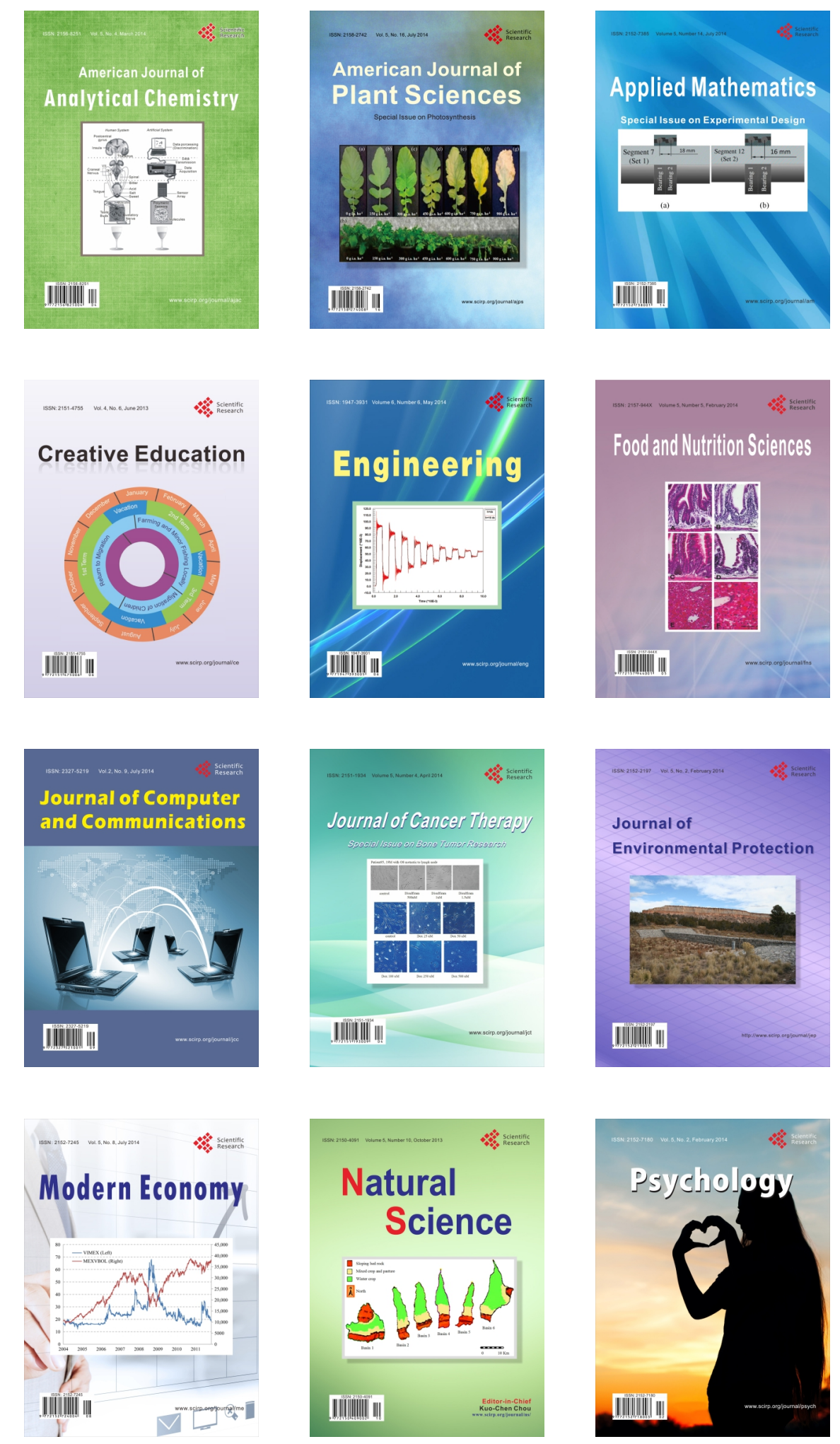